\title{
BIBECHANA
}

A Multidisciplinary Journal of Science, Technology and Mathematics

ISSN 2091-0762 (online)

Journal homepage: http://nepjol.info/index.php/BIBECHANA

\section{Mixing properties of Ni-Pd liquid alloy}

\author{
L. Gurung, R. P. Koirala, D. Adhikari" \\ Department of Physics, Mahendra Morang Adarsh Multiple Campus, Biratnagar, Nepal \\ *Email: adksbdev@yahoo.com
}

.Article history: Received 5 December, 2013

\section{Abstract}

In this work, thermodynamic and microscopic properties of Ni-Pd liquid alloy at $1873 \mathrm{~K}$ have been studied using a simple theory of mixture. In thermodynamic properties, free energy of mixing, heat of mixing and entropy of mixing have been studied. To understand the structural behaviour of the alloy concentration fluctuation in long wavelength limit and chemical short range order parameter have been computed. The Ni-Pd melt at $1873 \mathrm{~K}$ is found to be slightly deviated from regular behaviour. The best estimated value of energy parameter is found to be positive. The alloy is found to be weakly segregating system. The symmetric behaviour of all functions has been well explained by the simple theory of mixing

Keywords: Ideal alloys, regular alloys, non-ideal alloys, Ni-Pd alloy, thermodynamic functions

\section{Introduction}

The mixing behaviour of binary liquid alloys may be explained in terms of thermodynamic and microscopic properties. Thermodynamic behaviour of the alloys is understood by the knowledge of free energy of mixing $\left(\Delta \mathrm{G}_{\mathrm{M}}\right)$, heat of mixing $\left(\Delta \mathrm{H}_{\mathrm{M}}\right)$, entropy of mixing $\left(\Delta \mathrm{S}_{\mathrm{M}}\right)$ and activity (a). Structural behavior is comprehended by the interpretation of concentration fluctuation in long wavelength limit $\left(\mathrm{S}_{\mathrm{CC}}(0)\right)$ and chemical short range order parameter $\left(\alpha_{1}\right)$. The thermodynamic properties of binary liquid alloys give the information about the maximum stable composition, bonding strength and most mixed state of the alloy. The microscopic properties provide the information about the local arrangement of atoms.

It is, therefore, obvious that without having a clear knowledge of the properties of alloys in liquid state it is not possible to understand the energetics of the formation of solid alloys. This requirements demand extensive investigations for understanding the properties of alloys in the liquid state.

Several theoreticians [1-10] have long been carried out to understand various properties of alloys in their liquid states. The Ni-Pd alloy is used in hydrogen sensors. This alloy has also glass forming properties at eutectic region around $45 \%$ of Pd. The knowledge of thermodynamic and structural properties at liquid state is essential for investigating the solidification process. Hence, it is important to study different properties of Ni-Pd liquid alloy for its industrial applications. In this work we intend to study the thermodynamic and structural properties of Ni-Pd alloy in liquid state at $1873 \mathrm{~K}$ by using simple theory of mixing.

In next section the theoretical formalism is presented. Section 3 deals with results and discussion and conclusions are outlined in section 4. 


\section{Theoretical basis}

\section{Theoretical basis}

For non-ideal solution we have to take an account of the heat of formation $\Delta \mathrm{H}_{\mathrm{M}}$. Let's account for the heat of formation $\Delta \mathrm{H}_{\mathrm{M}} \neq 0$ using a simple model called statistical or quasi-chemical model. In this model the heat of mixing is only related to the bond energies between adjacent atoms. The assumption is that the interatomic distances and bond energies are independent of composition. There may be three types of bonds:

(i) A-A bonds (Energy $\left.\mathrm{E}_{\mathrm{AA}}\right)$ :

(ii) $\quad \mathrm{B}-\mathrm{B}$ bonds (Energy $\mathrm{E}_{\mathrm{BB}}$ )

(iii) $\quad \mathrm{A}-\mathrm{B}$ bonds $\left(\mathrm{E}_{\mathrm{AB}}\right)$

If there are $\mathrm{P}_{\mathrm{AA}}, \mathrm{P}_{\mathrm{BB}}, \mathrm{P}_{\mathrm{AB}}$ bonds of each type, the internal energy of the solution is

$$
\mathrm{E}=\mathrm{P}_{\mathrm{AA}} \mathrm{E}_{\mathrm{AA}}+\mathrm{P}_{\mathrm{BB}} \mathrm{E}_{\mathrm{BB}}+\mathrm{P}_{\mathrm{AB}} \mathrm{E}_{\mathrm{AB}}
$$

If $\mathrm{z}$ is the coordination number of an atom in a crystal, then the number of atoms $\mathrm{N}_{\mathrm{A}}$ and $\mathrm{N}_{\mathrm{B}}$ are related to the number of bonds

$$
\begin{aligned}
& \mathrm{N}_{\mathrm{A}} \mathrm{Z}=2 \mathrm{P}_{\mathrm{AA}}+\mathrm{P}_{\mathrm{AB}} \\
& \mathrm{N}_{\mathrm{B}} \mathrm{Z}=2 \mathrm{P}_{\mathrm{BB}}+\mathrm{P}_{\mathrm{AB}} \\
& \mathrm{P}_{\mathrm{AA}}=\frac{\mathrm{N}_{\mathrm{A}} \mathrm{Z}}{2}-\frac{\mathrm{P}_{\mathrm{AB}}}{2} \\
& \mathrm{P}_{\mathrm{BB}}=\frac{\mathrm{N}_{\mathrm{B}} \mathrm{Z}}{2}-\frac{\mathrm{P}_{\mathrm{AB}}}{2}
\end{aligned}
$$

Using these expressions for $\mathrm{P}_{\mathrm{AA}}$ and $\mathrm{P}_{\mathrm{BB}}$ in the expression for energy, we have

$$
\begin{aligned}
& \mathrm{E}=\frac{\mathrm{N}_{\mathrm{A}} \mathrm{Z}}{2}-\frac{\mathrm{P}_{\mathrm{AB}}}{2} \mathrm{E}_{\mathrm{AA}}+\frac{\mathrm{N}_{\mathrm{B}} \mathrm{Z}}{2}-\frac{\mathrm{P}_{\mathrm{AB}}}{2} \mathrm{E}_{\mathrm{BB}}+\mathrm{P}_{\mathrm{AB}} \mathrm{E}_{\mathrm{AB}} \\
& \mathrm{E}=\frac{\mathrm{N}_{\mathrm{A}} \mathrm{Z}}{2} \mathrm{E}_{\mathrm{AA}}+\frac{\mathrm{N}_{\mathrm{B}} \mathrm{Z}}{2} \mathrm{E}_{\mathrm{BB}}+\mathrm{P}_{\mathrm{AB}}\left(\mathrm{E}_{\mathrm{AB}}-\frac{\mathrm{E}_{\mathrm{AA}}+\mathrm{E}_{\mathrm{BB}}}{2}\right)
\end{aligned}
$$

The first two terms of right hand side of Eq. (7) represents the energy of unmixed components. Therefore energy of mixing (heat of formation $\left(\Delta \mathrm{H}_{\mathrm{M}}\right)$ ) is given as

$$
\Delta \mathrm{H}_{\mathrm{M}}=\mathrm{P}_{\mathrm{AB}}\left(\mathrm{E}_{\mathrm{AB}}-\frac{\mathrm{E}_{\mathrm{AA}}+\mathrm{E}_{\mathrm{BB}}}{2}\right)
$$

For small differences between $\mathrm{E}_{\mathrm{AB}}$ and $\left(\mathrm{E}_{\mathrm{AA}}+\mathrm{E}_{\mathrm{BB}}\right) / 2$ we can still consider a random arrangement of atoms in a solution and entropy of mixing of the solution is equal to ideal value $\left(\Delta \mathrm{S}_{\mathrm{M}}=-\mathrm{R}\left[\mathrm{X}_{1} \ln \mathrm{X}_{1}+\mathrm{X}_{2} \ln \mathrm{X}_{2}\right]\right)$. Such solutions are called regular solutions. Then

$$
\mathrm{P}_{\mathrm{AB}}=\mathrm{zN}_{\text {tot }} \mathrm{X}_{1} \mathrm{X}_{2}
$$

And

$$
\Delta \mathrm{H}_{\mathrm{M}}=\Theta \mathrm{X}_{1} \mathrm{X}_{2}
$$

where

$$
\Theta=\mathrm{zN}_{\text {tot }}\left(\mathrm{E}_{\mathrm{AB}}-\frac{\mathrm{E}_{\mathrm{AA}}+\mathrm{E}_{\mathrm{BB}}}{2}\right)
$$

called the exchange parameter. It measures how different $\mathrm{AB}$ interactions are from the $\mathrm{AA}$ and $\mathrm{BB}$ interactions. If all of the interactions among the components are the same, then and there is no energy of mixing. For regular solutions a random arrangement of atoms in a solution is assumed. If there is small deviation from regular solution we may have to correct the exchange parameter. For this case let us consider $\Theta$ is a linear function of $\mathrm{T}$ as [12] 


$$
\Theta=\Omega+\mathrm{T} \frac{\mathrm{d} \Omega}{\mathrm{dT}}
$$

Here, the term $\frac{\mathrm{d} \Omega}{\mathrm{dT}}$ is introduced in order to account the small deviation of entropy from ideal behaviour. Therefore, the heat of mixing and entropy of mixing may be expressed as

$$
\begin{aligned}
& \Delta \mathrm{H}_{\mathrm{M}}=\left(\Omega+\mathrm{T} \frac{\mathrm{d} \Omega}{\mathrm{dT}}\right) \mathrm{X}_{1} \mathrm{X}_{2} \\
& \Delta \mathrm{S}_{\mathrm{M}}=-\mathrm{R}\left(\mathrm{X}_{1} \ln \mathrm{X}_{1}+\mathrm{X}_{2} \ln \mathrm{X}_{2}\right)+\frac{\mathrm{d} \Omega}{\mathrm{dT}} \mathrm{X}_{1} \mathrm{X}_{2}
\end{aligned}
$$

Then the free energy of mixing of the regular solution is given as

$$
\Delta \mathrm{G}_{\mathrm{M}}=\mathrm{RT}\left[\mathrm{X}_{1} \ln \mathrm{X}_{1}+\mathrm{X}_{2} \ln \mathrm{X}_{2}\right]+\Omega \mathrm{X}_{1} \mathrm{X}_{2}
$$

The activity of pure components $\mathrm{A}$ and $\mathrm{B}$ in binary solution may be obtained using a standard statistical relation

$$
R T \ln a_{A}=\Delta G_{M}+X_{2} \frac{\partial \Delta G_{M}}{\partial X_{1}}
$$

Thus, we have

$$
\mathrm{RT} \ln \mathrm{a}_{\mathrm{A}}=\mathrm{RT} \ln \mathrm{X}_{1}+\Omega\left(1-\mathrm{X}_{1}\right)^{2}
$$

Similarly the activity of the component $\mathrm{B}$ may be obtained as

$$
\mathrm{RT} \ln \mathrm{a}_{\mathrm{B}}=\mathrm{RT} \ln \mathrm{X}_{2}+\Omega\left(1-\mathrm{X}_{2}\right)^{2}
$$

The expression for concentration fluctuation in long wavelength limit $\left(\mathrm{S}_{\mathrm{CC}}(0)\right)$ has been introduced and derived by Bhatia and March [13]. It provides the idea about ordering and segregating nature of a solution. If the computed value of $\mathrm{S}_{\mathrm{CC}}(0)$ is less than ideal values $\left(=\mathrm{X}_{1} \mathrm{X}_{2}\right)$ there is tendency of unlike atoms pairing (ordering) and if it is greater than ideal values $\left(=\mathrm{X}_{1} \mathrm{X}_{2}\right)$ there is a tendency of like atoms pairing (segregating).

According Bhatia and March[13] the concentration fluctuation in long wavelength limit may be related with the free energy of mixing by the relation

$$
\mathrm{S}_{\mathrm{CC}}(0)=\left[\mathrm{RT}\left(\partial^{2} \Delta \mathrm{G}_{\mathrm{M}} / \partial^{2} \mathrm{x}_{1}\right)^{-1}\right]_{\mathrm{T}, \mathrm{p}, \mathrm{N}}
$$

Therefore $\mathrm{S}_{\mathrm{CC}}(0)$ for regular solution is given as

$$
\mathrm{S}_{\mathrm{CC}}(0)=\frac{\mathrm{X}_{1} \mathrm{X}_{2}}{1-2 \mathrm{X}_{1} \mathrm{X}_{2} \frac{\Omega}{\mathrm{RT}}}
$$

A measure of the tendency to compound formation or phase separation in a molten alloy is also given by the Warren-Cowley short-range order parameter (SRO), $\alpha_{1}[14,15]$. This is an important indicator of the degree of ordering in a binary alloy and is given as

$$
\alpha_{1}=\frac{\mathrm{S}-1}{\mathrm{~S}(\mathrm{z}-1)+1}
$$

where

$$
\mathrm{S}=\frac{\mathrm{S}_{\mathrm{CC}}(0)}{\mathrm{S}_{\mathrm{CC}}^{\mathrm{id}}}
$$

$z$ being the coordination number of the alloy. We note that the main effect of $z$ on $\alpha_{1}$ is to reduce the depth and hence its magnitude, the significant effects of complex formation and phase separation are essentially maintained. 


\section{Result and Discussion}

We have estimated the best fit value of $\Omega$ by the successive approximation using the observed values of free energy of mixing [16] and Eq. (15). The value of $\Omega$ estimated by this method must satisfy all the thermodynamic and microscopic functions. In our case the best fit value of $\Omega$ is found to be 7350 $\mathrm{Jmol}^{-1}$. The value of $\Omega$ is found to be positive. This indicates that the Ni-Pd system in liquid state at $1873 \mathrm{~K}$ is segregating system, i.e. like atoms tend to form pairs. We have calculated the free energy of mixing of Ni-Pd liquid alloys at $1873 \mathrm{~K}$ using Eq. (15) and estimated value of $\Omega$. The computed values of free energy of mixing are almost equal to the observed values. Both the computed and observed values of free energy of mixing are minimum (computed value $=-8951 \mathrm{Jmol}^{-1}$ and observed value $\left.=8928 \mathrm{Jmol}^{-1}\right)$ at equiatomic composition. The free energy of mixing is negative at all composition (Fig. 1).

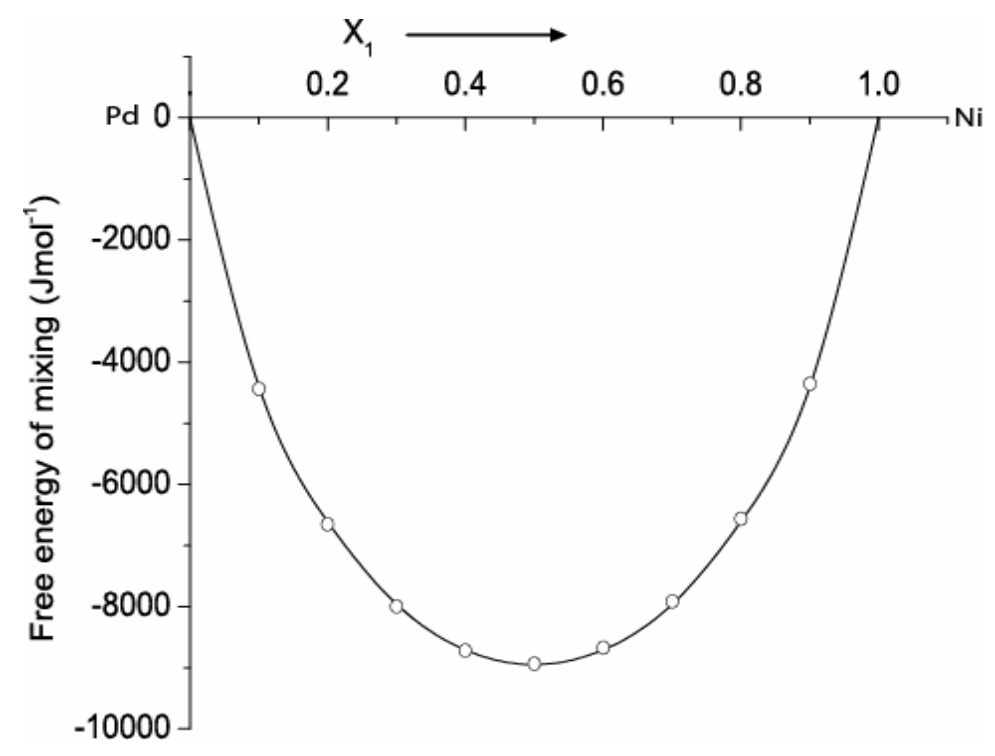

Fig. 1: Excess free energy of mixing $\left(\Delta \mathrm{G}_{\mathrm{M}}^{\mathrm{XS}}\right)$ of Ni-Pd liquid alloy at $1873 \mathrm{~K}$ versus $\mathrm{X}_{1}$ (Concentration of $\mathrm{Ni}$ ); solid lines for theoretical values and circles for experimental values.

We have computed the heat of mixing of Ni-Pd liquid alloys at $1873 \mathrm{~K}$ on the basis of simple theory of mixing (Eq. 13). Before this we estimated the best fit value of $\frac{\mathrm{d} \Omega}{\mathrm{dT}}$ using experimental data. Its best value is found to be $-1.4 \mathrm{Jmol}^{-1} \mathrm{~K}^{-1}$. The theoretical and experimental values are in a very good agreement up to $\mathrm{X}_{1}=0.6$ ( Fig. 32). Above this region there are some discrepancies. These discrepancies may be due to greater deviation of solution from regular behaviour. However, the symmetric nature of the experimental results of heat of mixing against the concentration of $\mathrm{Ni}$ is not violated by the theoretical analysis. Both the experimental and theoretical values of heat of mixing are positive at all compositions. The theoretical maximum value of heat of mixing is almost equal to the experimental maximum value (Experimental value $=1195.5 \mathrm{Jmol}^{-1}$, Theoretical value $=1182 \mathrm{Jmol}^{-1}$ ). We have then computed the entropy of mixing of Ni-Pd liquid alloys at $1873 \mathrm{~K}$ using Eq. (14). The computed entropy of mixing is in good agreement with the observed values at all compositions. The entropy of mixing is positive for all compositions. This clearly indicates that the entropy is greater in 
the mixture than that of the pure states of the components. The symmetric behaviour of the observed result of entropy of mixing of Ni-Pd liquid alloys at $1873 \mathrm{~K}$ is well explained by the theoretical analysis. For comparative study the computed and observed values of entropy of mixing of Ni-Pd liquid alloys at 1873 are plotted against concentration of Ni (Figure 3).

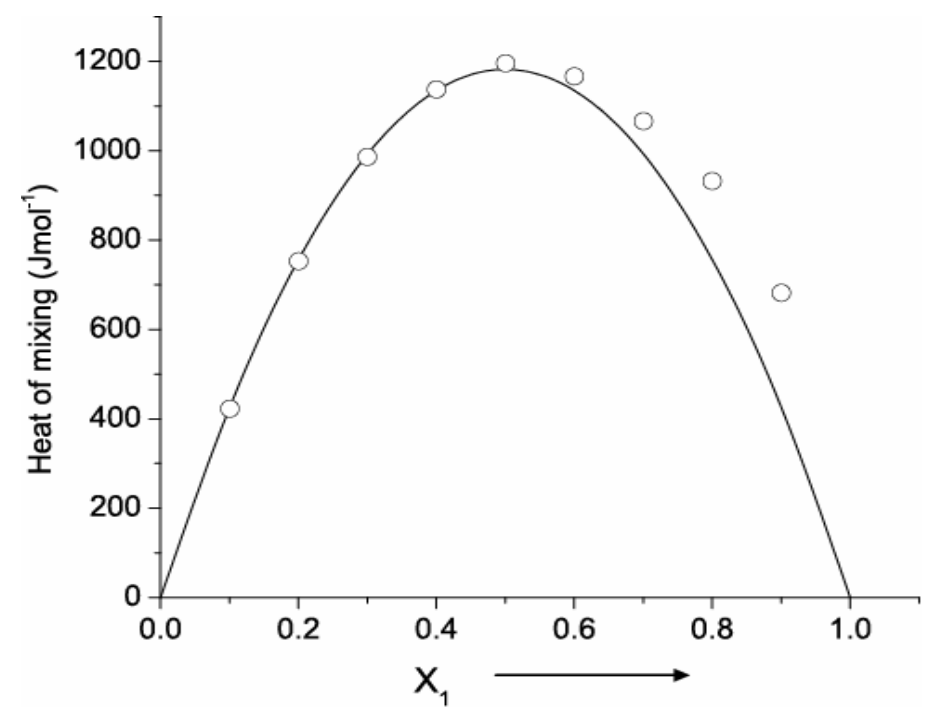

Fig. 2 : Heat of mixing $\left(\Delta \mathrm{H}_{\mathrm{M}}\right)$ of Ni-Pd liquid alloy at $1873 \mathrm{~K}$ versus $\mathrm{X}_{1}$ (Concentration of $\mathrm{Ni}$ ) ; solid lines for theoretical values and circles for experimental values

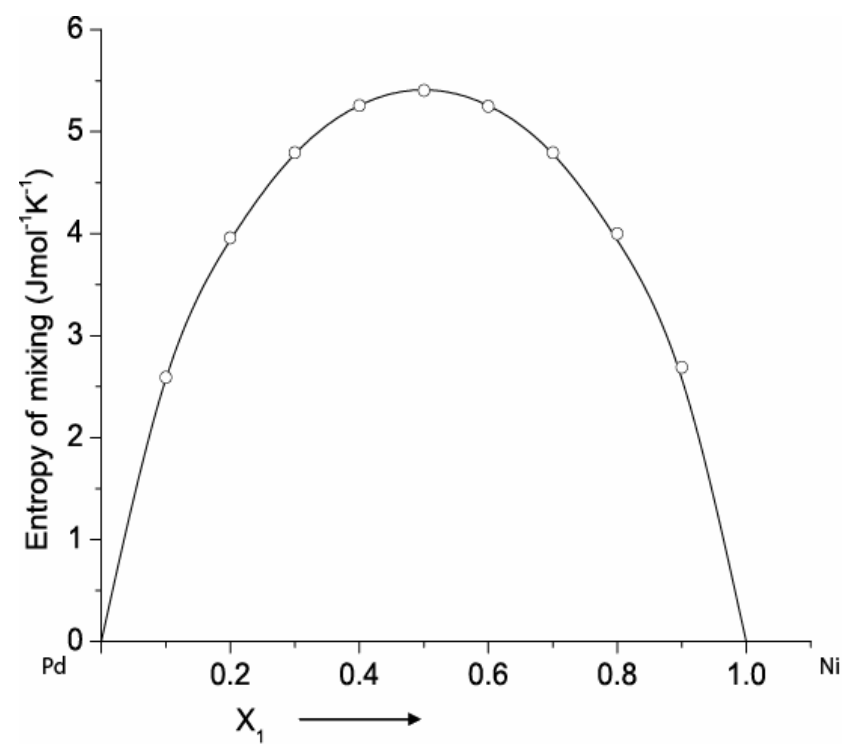

Fig. 3: Heat of mixing $\left(\Delta \mathrm{S}_{\mathrm{M}}\right)$ versus $\mathrm{X}_{1}$ (Concentration of Ni) for different positive values of $\frac{d \Omega}{d T}$; solid lines for theoretical values and circles for experimental values.

We have computed the theoretical values of $\mathrm{S}_{\mathrm{CC}}(0)$ for Ni-Pd liquid alloys at $1873 \mathrm{~K}$ using the previously determined value of $\Omega$ (Figure 4). The computed value of $\mathrm{S}_{\mathrm{CC}}(0)$ is greater than ideal values at all compositions. This shows that the alloy under investigation is segregating in nature. This 
result is in agreement with the theoretical and experimental analysis of free energy of mixing and heat of mixing. The symmetric behaviour of $\mathrm{S}_{\mathrm{CC}}(0)$ is well explained by the theoretical analysis.

The knowledge of $\alpha_{1}$ provides an immediate insight into the nature of the local arrangements of atoms in the mixture. At equiatomic composition, one has $-1 \leq \alpha_{1} \leq 1$. The minimum possible value of $\alpha_{1}$ is $\alpha_{1}^{\min }=-1$ and that implies complete ordering of unlike atoms paring at nearest neighbours. On the other hand the maximum value of $\alpha_{1}$ is $\alpha_{1}^{\max }=+1$ which implies total segregation leading to the phase separation and $\alpha_{1}=0$ corresponds to a random distribution of atoms. Here $\alpha_{1}$ can be estimated from the knowledge of $\mathrm{S}_{\mathrm{CC}}(0)$ as by the Eq. (21). It is found positive at all compositions. This shows that Ni-Pd liquid alloys at $1873 \mathrm{~K}$.

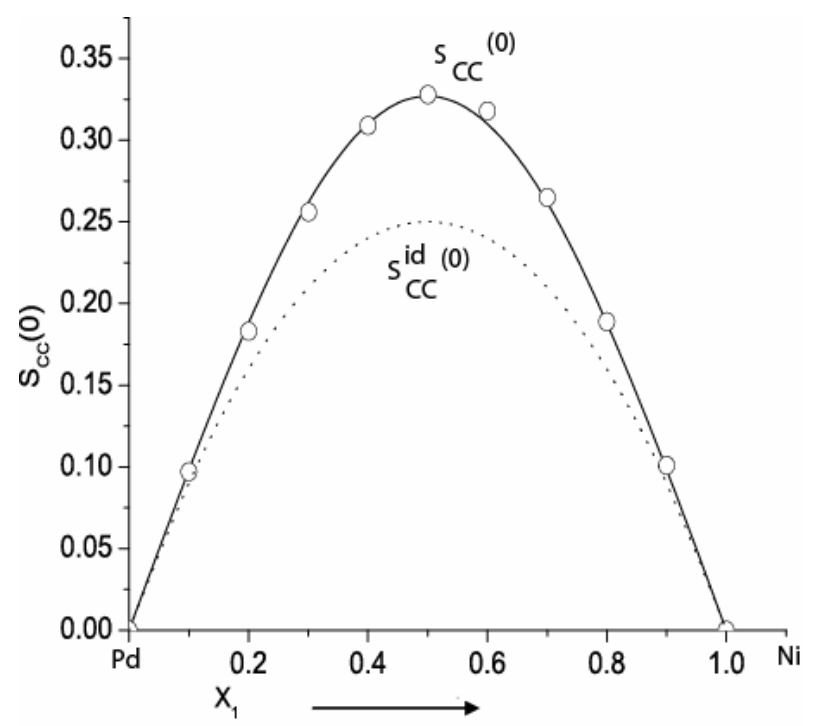

Fig. 4: Concentration fluctuation in long wavelength limit $\left(\mathrm{S}_{\mathrm{CC}}(0)\right)$ versus $\mathrm{X}_{1}$ (Concentration of $\mathrm{Ni}$ ) for Ni-Pd liquid alloys at $1873 \mathrm{~K}$; solid lines for theoretical values, circles for experimental values and dotted lines for ideal values.

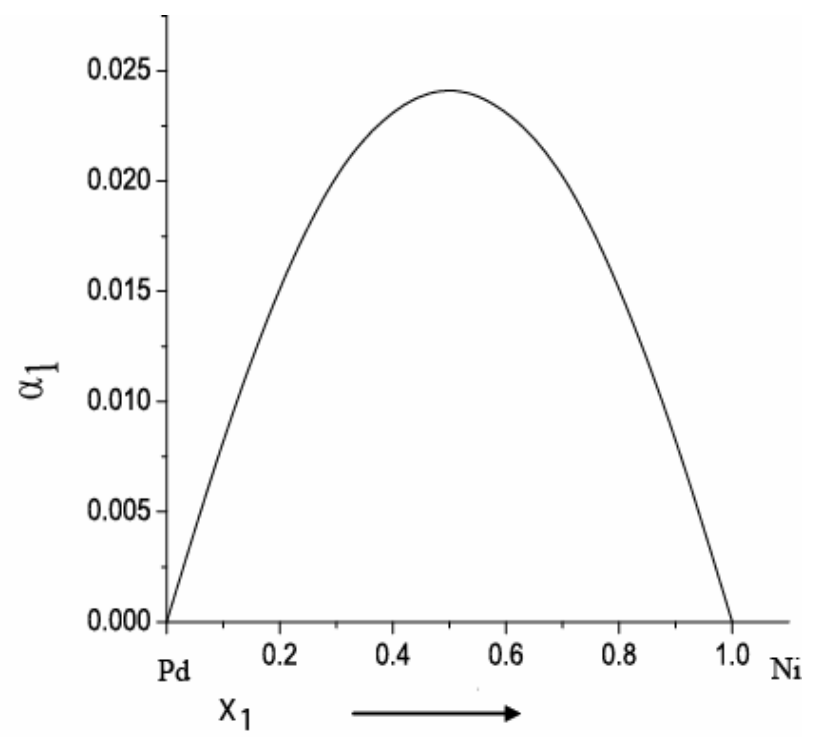

Fig. 5: Chemical short range order parameter $\left(\alpha_{1}\right)$ versus $X_{1}$ (Concentration of Ni) for Ni-Pd liquid alloys at $1873 \mathrm{~K}$ 


\section{Conclusions}

Based on the above discussion the following conclusions may be drawn about Ni-Pd liquid alloy at $1873 \mathrm{~K}$ :

(i) It is not a strictly regular solution. It slightly deviates from the regular behaviour.

(ii) It is a weakly interacting system.

(iii) It is a segregating alloy, i.e. like atoms tend to pair forming homo-coordination.

(iv) All the thermodynamic and structural functions of this alloy are symmetric at equiatomic composition as a function of concentration.

\section{References}

1. K. Hoshino and W.H. Young, J. Phys. F 10 (1980) 1365.

2. R.N. Singh and F. Sommer, Z.Metall. 83 (1992) 553.

3. I.S. Jha, R. N. Singh, P.L. Shrivastava and N.R. Mitra, Phil. Mag. 61 (1990) 15.

4. D.Ahhikari, I.S.Jha and B.P.Singh, Physica B, 405(2010)1861

5. J.R. Wilson, Metallurgical Review 10 (1965) 381.

6. A.B. Bhatia and N.H. March, J. Phys.F:Met. Phys. 5 (1975) 1100.

7. R. N. Singh, I.S. Jha and D.K. Pandey, J. Condens. Matter 5(1993) 2469.

8. S. Lele and P. Ramchandrarao, Metall. Trans. 12 B (1981) 659.

9. A.S. Jordan, Metall. Trans. 1 (1970) 239.

10. D.Ahhikari, B.P.Singh and I.S.Jha,, Phys. Chem. Liq. (2010)

11. Segvi K.O. (2004). Physical properties of Pd, Ni metals and their binary alloys. Ph.D. Thesis.A. Guggenheim,. Mixtures, Clarendon Press, Oxford, 1952.

12. A.B. Bhatia and N.H. March, J. Phys.F:Met. Phys. 5(1975) 1100.

13. E.Warren, X-ray Diffraction (Reading MA: Addison-Wesley (1969) p.227.

14. J.M. Cowley Phys. Rev. 77, (1950) 667.

15. R. Hultgren, P. D.Desai, D.T. Hawkins, M. Gleiser and K.K. Kelley, Selected Values of the Thermodynamic Properties of Binary Alloys (ASM,Metal Park,1973). 